Original Research Paper

\title{
Etiology of Meningitis from Patients Suspected of Meningitis Attending Tribhuvan University Teaching Hospital, Kathmandu, Nepal
}

\author{
${ }^{1}$ Pinky Pandey, ${ }^{2}$ Bharat Jha and ${ }^{3}$ Anima Shrestha \\ ${ }^{I}$ Department of Microbiology, St. Xavier's College, Maitighar, Kathmandu, Nepal \\ ${ }^{2}$ Department of Biochemistry, Institute of Medicine, Tribhuvan University Teaching Hospital, Kathmandu, Nepal \\ ${ }^{3}$ Department of Microbiology, Tri Chandra College, Kathmandu, Nepal
}

Article history

Received: 29-03-2015

Revised: 08-06-2015

Accepted: 20-06-2015

Corresponding Author:

Pinky Pandey

Department of Microbiology,

St. Xavier's College,

Maitighar, Kathmandu, Nepal

Email: mercy.piku@gmail.com

\begin{abstract}
Meningitis is an inflammatory infection of the membranes surrounding the brain and spinal cord, which occurs either as a primary disease or secondarily to disease in some other parts of the body. Its most frequent causes are Neisseria meningitidis, Streptococcus pneumoniae and Haemophilus influenzae. The epidemiological trend of acute meningitis varies with time and geography. Information on the relative frequency of the isolation and antibiotic susceptibility patterns of these pathogens is scarce in Nepal. To analyze the various causative agents of meningitis in all age group patients and to know the antimicrobial susceptibility pattern of bacterial isolates from the Cerebrospinal Fluids (CSF) of suspected cases of meningitis, were the prime objectives of this paper. In this cross sectional study, a total $356 \mathrm{CSF}$ specimens were collected from patients suspected of meningitis and processed macroscopically, microscopically and microbiologically by standard microbiological methods in Emergency Laboratory of Tribhuvan University Teaching Hospital (TUTH) Kathmandu, Nepal over a period of six months, from March to August 2014. Out of 356 CSF samples, $16(4.5 \%)$ were found to be culture positive. Among the culture positive isolates, the most common bacterial isolate was Staphylococcus aureus, 4(25\%). Isolation rate of Cryptococcus neoformans, the only fungal etiology of meningitis, was $3(18.8 \%)$, which was seen in elderly patients indicating increased susceptibility of $C$. neoformans in immune-compromised status of patients. All bacterial isolates were found to be sensitive to Chloramphenicol. The isolation rate of pathogens causing meningitis from $\mathrm{CSF}$ is low (4.5\%). Chloramphenicol may be used for the treatment of bacterial meningitis.
\end{abstract}

Keywords: Meningitis, Antimicrobial Susceptibility

\section{Introduction}

Meningitis is one of the medical emergencies related to infectious diseases, which is potentially associated with a high rate of complications. The term Meningitis is used to describe an inflammation of the membranes that surround the brain or the spinal cord. According to Mahmoud and Abd-ElSadik (2013) the World Health Organization (WHO) indicates that each year registers nearly half a million new cases suffering from meningitis and WHO (2005) estimates that bacterial meningitis affects approximately 1.2 million people each year globally and causes almost 170,000 deaths worldwide each year. There is also paucity of objective data on the causative agents of meningitis and their susceptibility in Nepalese population (Ansari and Pokhrel, 2011). Due to the urgency associated with the treatment of meningitis, there is, therefore, the need to have knowledge of the causative agents and their susceptibility profiles to come to better decisions of the empirical treatment. Thus the aim of this paper is to analyze the etiology of meningitis and to determine the antibiotic susceptibility 
pattern of the bacterial isolates. Antimicrobial susceptibility testing of bacterial isolates would help us determine the sensitivity patterns of these isolates, thereby reducing antibiotics misuse and the incidence of microbial drug resistance.

\section{Etiology of Meningitis}

Generally, the meningitis is of infectious etiology that can be viral, bacterial, fungal, or parasitic in nature, but bacteria remain the common etiological agent (Nagarathna et al., 2012). However, some non-infectious causes of meningitis also exist. Non-infectious meningitis can emerge from administration of certain drugs such as non-steroidal anti-inflammatory drugs, immunoglobulins or some antibiotics. It can also develop from diseases like sarcoidosis and neoplastic meningitis. Infectious meningitis can be further sub-divided to nonbacterial and bacterial (pyogenic) meningitis. Nonbacterial meningitis is typically caused by viral or fungal infections (Al Bekairy et al., 2014).

The three most common bacterial pathogens causing bacterial meningitis worldwide are Haemophilus influenzae type b (Hib), Neisseria meningitidis and Streptococcus pneumoniae, which together account for about $80 \%$ of all cases. Over two-thirds of all cases of bacterial meningitis occur in children less than five years old. Meningococcus affects all ages, most cases occurring in children and adolescents. More than $80 \%$ of meningitis caused by $H$. influenzae occurs in children less than 5 years old (Andargachew et al., 2005).

In developed countries, endemic of meningitis is generally caused by serogroups $\mathrm{B}$ and $\mathrm{C}$ of $N$. meningitidis. Epidemics in developed countries are typically caused by serogroup $\mathrm{C}$ although epidemics due to serogroup B have also occurred in Brazil, Chile, Cuba, Norway and more recently in New Zealand (CDC, 1998).

Strep. pneumoniae is a major cause of childhood bacterial meningitis in countries where Hib disease has been eliminated by vaccination. It is the second most frequently reported cause of septic meningitis in some European and sub-Saharan African countries, after meningococcal cases (Ceyhan et al., 2008). In the United States, for example, after the introduction of $H$. influenzae type $\mathrm{b}$ vaccination, the commonest causes of bacterial meningitis in all age groups are pneumococcal, meningococcal, Group B streptococci, Listeria monocytogenes and $H$. influenzae type $\mathrm{b}$, in decreasing order of incidence (Schuchat et al., 1997).

Currently, serogroups $\mathrm{A}$ and $\mathrm{C}$ of $N$. meningitides predominate throughout Asia and Africa, whereas serogroups $\mathrm{B}$ and $\mathrm{C}$ are responsible for most cases in Europe and North America. In several countries, including the United States, the proportion of disease caused by serogroup $\mathrm{Y}$ has increased over the past decade. Serogroup W-135 has also recently emerged in some parts of the world, primarily in the Middle East and Africa (Ceyhan et al., 2008). Among children in England and Wales, the commonest causes are meningococcal, $H$. influenzae type $\mathrm{b}$, pneumococcal, Group B streptococci, Escherichia coli, Listeria species and staphylococci (Davison and Ramsay, 2003). In Hong Kong, the commonest cause of non-viral meningitis is tuberculous meningitis, accounting for more than $15 \%$ of meningitis in children. Bacterial meningitis, on the other hand, is uncommon (Sung et al., 1997). Similarly, Streptococcus agalactiae was the commonest cause in adult bacterial meningitis in Singapore and Hong Kong (Wilder-Smith, 2000).

E. coli and Group B Streptococci cause the majority of neonatal meningitis in the developed countries, whereas Klebsiella species has been the most common CSF bacterial pathogen isolated in studies from Kenya, Jordan and Ethiopia (Laving et al., 2003).

The uncommon pathogens are Staphylococcus aureus and Pseudomonas aeruginosa. Mycobacterium tuberculosis is the less frequent of bacterial meningitis. Many viruses have the ability of causing meningitis such as Echovirus, Coxasackie virus type $\mathrm{A}$ and $\mathrm{B}$, Herpes simplex virus type 1 and 2, Epstein barr virus, HIV, Vricella-zoster virus and Cytomegalovirus (AL-Zubiery, 2001). Non-polio enteroviruses are the most common cause of viral meningitis in the United States (CDC, 2015b).

In addition, to bacterial and viral agents, fungi may also cause meningitis like Cryptococcus neoformans and Candida, which are the most common fungi isolated from CSF. Parasite such as Naegleria has also been identified as a causative agent of meningitis (AL-Zubiery, 2001). Cryptococcus disease is one of the most common causes of adult meningitis in Africa (CDC, 2015a).

Thus the pathogens causing meningitis varies with time, geography and age of people across different regions of the world.

\section{Objectives}

- To isolate and identify the etiological agents of meningitis

- To correlate the CSF staining and culture results

- To determine antibiotic susceptibility pattern of the bacterial isolates

\section{Materials and Methods}

\section{Study Design}

This is a cross sectional study carried out at the Emergency Laboratory in Tribhuvan University Teaching Hospital (TUTH) from March to August 2014 over a period of six months. 


\section{Study Sample}

During the study, all patients suspected of meningitis who attended the Emergency Laboratory at TUTH within the specified period (March to August 2014), were included as sample of the study.

\section{Sample Size}

No predefined sample size was set. A total 356 patient CSF samples who were suspected of meningitis at TUTH between the periods of March to August 2014, were included in the study.

\section{Specimen Collection}

CSF samples were collected in the Hospital by experienced medical officer by lumbar puncture on immediate arrival of the cases with clinical suspicion of meningitis. A sterile wide-bore needle was inserted between L4-L5 lumbar vertebrae and the CSF was allowed to drip into a dry sterile container. About $3 \mathrm{~mL}$ of CSF was collected in sterile container with all aseptic precautions and brought to the laboratory immediately. A total 356 CSF samples were collected. Patients unfit for lumbar puncture were excluded from the study.

\section{Sample Processing}

The CSF procedures performed included macroscopic observation of CSF appearance and color, Gram staining, culture and antibiotic sensitivity test. CSF specimens were prepared for microscopic examination by centrifugation at $1000 \times \mathrm{g}$ for $10 \mathrm{~min}$ at room temperature.

The sediment was thoroughly mixed and used for Gram staining. After conventional Gram staining, slides were examined by light microscopy at $\times 40$ magnification and then at $\times 100$ magnification under oil immersion. The presence of organisms and their morphologies were reported. Besides Gram staining, India Ink preparation was also carried out to identify fungal organisms.

For culture, approximately $1 \mathrm{ml}$ of the deposit of the centrifuged CSF specimen were inoculated onto plates of Chocolate Agar (CA), Blood Agar (BA), MacConkey Agar (MA), Mannitol Salt Agar (MSA), Nutrient Agar (NA) and Sabouraud Dextrose Agar (SDA). For bacterial isolates, $\mathrm{BA}$ and $\mathrm{CA}$ plates were incubated in candle jar $\left(5-10 \% \mathrm{CO}_{2}\right)$ at $37^{\circ} \mathrm{C}$ for overnight. $\mathrm{MA}$ plates were incubated at $37^{\circ} \mathrm{C}$ in incubator for overnight. SDA plates were used for culture of fungal isolates and incubated at $37^{\circ} \mathrm{C}$ for $2-3$ days. All plates were read daily up to four days and plates with no visible growth were reincubated. Specimens with positive Gram's stain and negative culture were held for one week.

\section{Identification of Isolates}

Firstly, pure form of the culture was obtained from the primary culture by using purity plate and then it was processed for colony morphology, as well as staining and different biochemical tests following standard microbiological procedures to identify the organisms.

For Gram-positive organisms, following biochemical tests were done: Catalase, Oxidase and Coagulase tests. Optochin disc and Bacitracin discs were also placed on the subcultured plate in order to differentiate Pneumococcus from other Gram-positive cocci. Bile Solubility Test was also done for the identification of Strep. pneumoniae.

The biochemical tests used for the identification of Gram-negative bacterial isolates included Catalase Test, Oxidase Test, Indole Test, Methyl Red Test, VogesProskauer Test, Citrate Utilization Test, Triple Sugar Iron Test, Urease Test, Motility Test, OxidationFermentation Test and Gas Production Tests.

' $\mathrm{X}$ ' and ' $\mathrm{V}$ ' factor was used to identify the colony of $H$. influenzae. The presence or absence of growth was observed around the paper disc impregnated with ' $\mathrm{X}$ ' factor alone, ' $\mathrm{V}$ ' factor alone or ' $\mathrm{X}+\mathrm{V}$ ' factor, placed on a nutrient agar.

C. neoformans were identified based on colonial morphology, microscopic morphology of yeast cells and biochemical tests. Seventy-two $h$ after incubation, the isolates were subcultured to obtain single colonies on SDA plate. Presence of a capsule on India ink preparation and Urease Test were also used to confirm C. neoformans.

\section{Antibiotic Susceptibility Testing}

Antibiotic susceptibility testing was done using standard Kirby-Bauer disk diffusion method following Clinical and Laboratory Standards Institute (CLSI) guidelines. The antibiotics disc used in this study were Ampicillin $(10 \mu \mathrm{g})$, Amikacin $(30 \mu \mathrm{g})$, Cefotaxime $(30 \mu \mathrm{g})$, Erythromycin $(15 \mu \mathrm{g})$, Ceftriaxone $(30 \mu \mathrm{g})$, Ofloxacin $(5 \mu \mathrm{g})$, Chloramphenicol $(30 \mu \mathrm{g})$, Ciprofloxacin $(5 \mu \mathrm{g})$, Cotrimoxazole $(1.25 / 23.75 \mu \mathrm{g})$, Ceftazidime (30 $\mu \mathrm{g})$, Gentamicin $(10 \mu \mathrm{g})$ and Meropenem $(10 \mu \mathrm{g})(\mathrm{Hi}$ Media Laboratory Ltd, Mumbai, India).

The pure culture of the isolates were inoculated into Nutrient broth and incubated for about four $h$ at $37^{\circ} \mathrm{C}$ and then using a sterile swab the organism was swabbed on Mueller Hinton Agar (MHA) surface plate. For the isolates like Strep. pneumoniae, MHA containing $10 \%$ of sheep blood was used for testing its antibiotic susceptibility.

The surface was lightly and uniformly inoculated by cotton swab. Prior to inoculation, the swab stick was dipped into bacterial suspension having visually equivalent turbidity to $0.5 \mathrm{McF}$ arland standards. The swab stick was then took out and squeezed on the wall of the test tube to discard extra suspension. The plate was left to dry before application of discs. The antibiotic discs were applied to the agar surface using a disc dispenser. The plates were then incubated at $37^{\circ} \mathrm{C}$ for overnight. MHA containing 10\% BA plates and CA plates were incubated anaerobically in candle jar incubator for overnight. Results were scored as 
susceptible, intermediate susceptible or resistant, according to the CLSI criteria.

Control strains of E. coli (ATCC 25922), Staph. aureus (ATCC 25923) and Ps. aeruginosa (ATCC 27853) were also tested as a part of quality control.

\section{Data Collection and Statistical Analysis}

The demographic details (age and sex) and clinical data were recorded on standardized forms at admission and data collection was entirely embedded into the clinical routine.

Data analysis was carried out using Statistical Package for the Social Sciences (SPSS) version 20 and excel was used for the graphs. For each pathogens their frequencies and percentages among all CSF cultures and antimicrobial susceptibility profile were determined. As inferential statistics, Chi square test was performed in order to identify the association between cases of meningitis and the age groups and sex of patients, if any relationship between the variables could be identified. All tests of significance were two-tailed and a P-value less than 0.05 was considered to be significant.

\section{Results}

There was a slight male dominance in the sex ratio $(1.3: 1)$ with males contributing $56.5 \%$ and females $43.5 \%$ among the total 356 processed CSF samples (Fig. 1). The mean age of the patients was 27.8 years.

Among the total processed specimen $(\mathrm{N}=356)$, only $16(4.5 \%)$ CSF cultures were positive. Of the 16 culture positive cases, bacterial pathogens were isolated in $13(81.3 \%)$ cases whereas C. neoformans was the only fungal isolate isolated in 3(18.8\%) cases. Among 13 bacterial isolates, Staph. aereus was the predominant organism 4(30.8\%), followed by E. coli 3(23.1\%), Strep. pneumoniae $3(23.1 \%), \quad H$. influenzae $1(7.7 \%)$, Ps. aeruginosa 1(7.7\%) and Kl. pneumoniae 1(7.7\%) (Table 2).

The incidence of meningitis was not found to be statistically significant $(\mathrm{p}>0.05)$ with the age groups $(\leq 14$ and $>14$ years) and also across the sex of the patients included in this study $(\mathrm{p}>0.05)$ (Table 1).

\section{Gross Appearance and Culture Positive Isolates}

The isolation rate of pathogens from purulent CSF samples was highest 75\% (3/4) among all colored CSF samples, followed by cloudy samples $53.8 \%(7 / 13)$, slightly turbid $7.7 \%(3 / 39)$ and bloody samples $3.5 \%$ $(2 / 57)$ (Table 3$)$. One pathogen was also isolated from clear colored CSF samples.

\section{Staining and Culture Results}

More number (19) of isolates was identified on Gram staining than on the CSF culture (16). CSF culture didn't show the growth of $N$. meningitidis.

Similarly Staph. aureus and $\mathrm{Kl}$. pneumoniae each, in one case, was not identified on CSF culture (Table 4). However a high degree of positive correlation $(r=0.933)$ was found in between the isolates identified from CSF culture and Gram staining technique.

\section{Antibiotic Susceptibility Test of Bacterial Isolates}

Among the 12 antibiotics used against bacterial isolates, Chloramphenicol showed $100 \%$ efficacy followed by Ciprofloxacin $61.5 \%$ (Table 5 and 6).

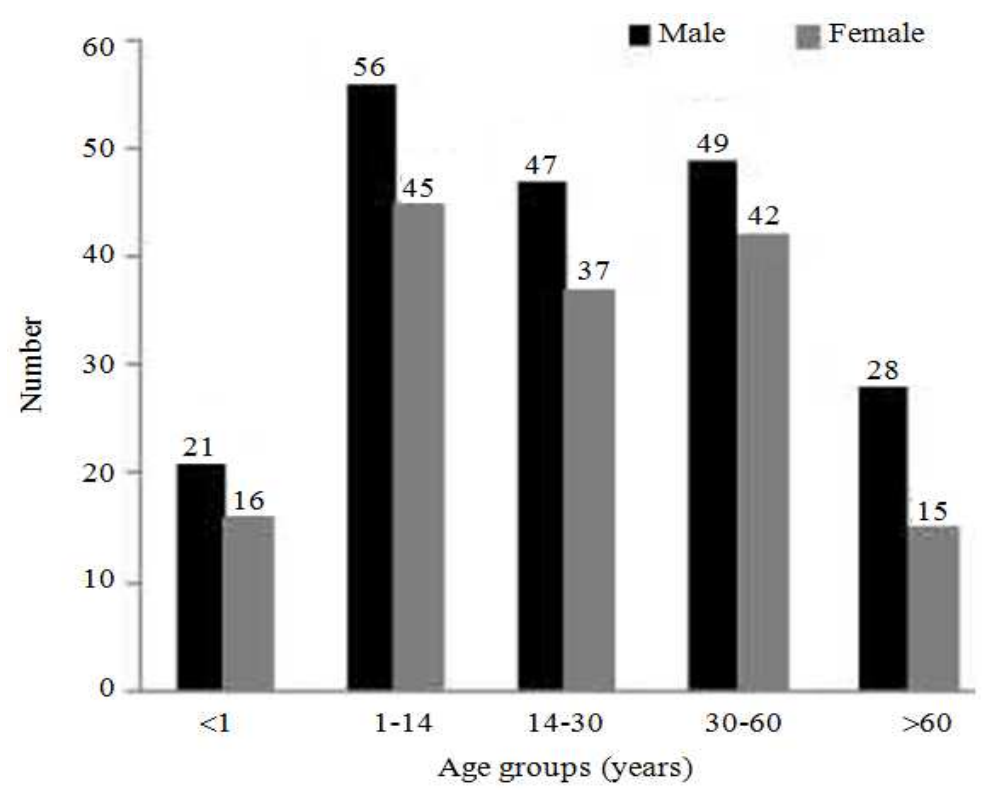

Fig. 1. Age and sex wise distribution of suspected cases of meningitis 
H. influenzae was found to be resistant against Ampicillin whereas susceptible against Ceftriaxone, Chloramphenicol, Ciprofloxacin, Cotrimoxazole and Erythromycin.

Chloramphenicol was found to be highly sensitive $3(100 \%)$ against $E$. coli, followed by Ceftriaxone $2(66.7 \%)$ and equally susceptibile agaist Amikacin, Cefotaxime, Cotrimoxazole and Ofloxacin 1(33.3\%) each. Cefotaxime, Chloramphenicol, Cotrimoxazole and Ofloxacin were $100 \%$ effective against $\mathrm{Kl}$. pneumoniae. Amikacin and Ciprofloxacin were ineffective against $\mathrm{Kl}$. pneumoniae. Ps. aeruginosa was found to be susceptible against Amikacin, Chloramphenicol, Ciprofloxacin, Meropenem and Ofloxacin but resistant against Gentamicin.

Amikacin, Ceftazidime and Chloramphenicol were $100 \%$ effective against Staph. aureus followed by Cefotaxime, Ciprofloxacin and Ofloxacin (75\%) each. Ampicillin, Chloramphenicol, Ciprofloxacin and Erythromycin were found to be highly 3(100\%) effective against Strep. pneumoniae followed by Cefotaxime $2(66.7 \%)$ and Cotrimoxazole was ineffective in 2(66.7\%) cases against Strep. pneumoniae.

Table 1. Association of meningitis with age groups and sex

\begin{tabular}{|c|c|c|c|c|}
\hline & & Patients with meningitis & Patients without meningitis & Total \\
\hline \multicolumn{5}{|l|}{$\begin{array}{l}\text { Age groups } \\
x^{2}=0.891, \mathrm{df}=1, \mathrm{p}=0.345, \mathrm{~ns}\end{array}$} \\
\hline & $0-14$ years & 8 & 130 & 138 \\
\hline & $>14$ years & 8 & 210 & 218 \\
\hline & Total & 16 & 340 & 356 \\
\hline \multicolumn{5}{|l|}{$\begin{array}{l}\text { Sex } \\
x^{2}=0.000, \mathrm{df}=1, \mathrm{p}=0.986, \mathrm{~ns}\end{array}$} \\
\hline & Male & 9 & 192 & 201 \\
\hline & Female & 7 & 148 & 155 \\
\hline & Total & 16 & 340 & 356 \\
\hline
\end{tabular}

$(\mathrm{df}=$ degree of freedom, $\mathrm{ns}=$ not significant $)$

Table 2. Laboratory confirmed cases of meningitis and their etiology

\begin{tabular}{lll}
\hline & Etiologies & Frequency $(\%)$ \\
\hline & Staph. aureus & $4(25.0)$ \\
Bacterial meningitis $(\mathrm{N}=13)$ & E. coli & $3(18.8)$ \\
& Strep. pneumoniae & $3(18.8)$ \\
& H. influenzae & $1(6.3)$ \\
Fungal meningitis $(\mathrm{N}=3)$ & Kl. pneumoniae & $1(6.3)$ \\
Total & Ps. aeruginosa & $1(6.3)$ \\
\hline
\end{tabular}

Table 3. Appearances of total CSF specimen and culture positive isolates

\begin{tabular}{lllll}
\hline & Total CSF samples $(\mathrm{N}=356)$ & Culture positive isolates $(\mathrm{N}=16)$ \\
Appearances of CSF & Frequency $(\mathrm{N})$ & Percentage $(\%)$ & Frequency $(\mathrm{N})$ & Isolation rate $(\%)$ \\
\hline Clear & 243.0 & 68.3 & 1.0 & 0.4 \\
Slightly turbid & 39.0 & 11.0 & 3.0 & 7.7 \\
Cloudy & 13.0 & 3.7 & 7.0 & 53.8 \\
Purulent & 4.0 & 1.1 & 3.0 & 75.0 \\
Bloody & 57.0 & 16.0 & 2.0 & 3.5 \\
\hline
\end{tabular}

Table 4. Correlation between isolated pathogens on CSF staining and culture

\begin{tabular}{llll}
\hline Organisms observed on & & No. of isolates on staining & No. of isolates on culture \\
\hline Gram staining & & 5 & 4 \\
& Staph. aureus & 3 & 3 \\
& E. coli & 3 & 3 \\
& Strep. Pneumoniae & 2 & 1 \\
& Kl. Pneumoniae & 1 & 1 \\
& H. influenzae & 1 & 1 \\
Ps. Aeruginosa & N. meningitidis & 1 & 0 \\
Total & C. neoformans & 3 & 3 \\
\hline
\end{tabular}


Table 5. Antibiotic susceptibility test of gram negative isolates

\begin{tabular}{|c|c|c|c|c|}
\hline \multirow[b]{2}{*}{ Organisms/antibiotics used } & & \multicolumn{3}{|c|}{ Susceptibility pattern } \\
\hline & & Susceptible & Intermediate & Resistant \\
\hline \multicolumn{5}{|l|}{ H. influenzae $(\mathrm{N}=1)$} \\
\hline & Ampicillin & 0 & 0 & 1 \\
\hline & Ceftriaxone & 1 & 0 & 0 \\
\hline & Chloramphenicol & 1 & 0 & 0 \\
\hline & Ciprofloxacin & 1 & 0 & 0 \\
\hline & Cotrimoxazole & 1 & 0 & 0 \\
\hline & Erythromycin & 1 & 0 & 0 \\
\hline \multicolumn{5}{|l|}{ E. $\operatorname{coli}(\mathrm{N}=3)$} \\
\hline & Amikacin & 1 & 0 & 2 \\
\hline & Cefotaxime & 1 & 1 & 1 \\
\hline & Ceftriaxone & 2 & 0 & 1 \\
\hline & Chloramphenicol & 3 & 0 & 0 \\
\hline & Cotrimoxazole & 1 & 0 & 2 \\
\hline & Ofloxacin & 1 & 1 & 1 \\
\hline \multicolumn{5}{|l|}{ Kl.pneumoniae $(\mathrm{N}=1)$} \\
\hline & Amikacin & 0 & 0 & 1 \\
\hline & Cefotaxime & 1 & 0 & 0 \\
\hline & Chloramphenicol & 1 & 0 & 0 \\
\hline & Ciprofloxacin & 0 & 0 & 1 \\
\hline & Cotrimoxazole & 1 & 0 & 0 \\
\hline & Ofloxacin & 1 & 0 & 0 \\
\hline \multicolumn{5}{|l|}{ Ps. aeruginosa $(\mathrm{N}=1)$} \\
\hline & Amikacin & 1 & 0 & 0 \\
\hline & Chloramphenicol & 1 & 0 & 0 \\
\hline & Ciprofloxacin & 1 & 0 & 0 \\
\hline & Gentamicin & 0 & 0 & 1 \\
\hline & Meropenem & 1 & 0 & 0 \\
\hline & Ofloxacin & 1 & 0 & 0 \\
\hline
\end{tabular}

Table 6. Antibiotic susceptibility test of gram positive isolates

\begin{tabular}{|c|c|c|c|c|}
\hline \multirow[b]{2}{*}{ Organisms/antibiotics use } & & \multicolumn{3}{|c|}{ Susceptibility pattern } \\
\hline & & Susceptible & Intermediate & Resistant \\
\hline \multicolumn{5}{|c|}{ Staph. aureus $(\mathrm{N}=4)$} \\
\hline & Amikacin & 4 & 0 & 0 \\
\hline & Cefotaxime & 3 & 0 & 1 \\
\hline & Ceftazidime & 4 & 0 & 0 \\
\hline & Chloramphenicol & 4 & 0 & 0 \\
\hline & Ciprofloxacin & 3 & 1 & 0 \\
\hline & Ofloxacin & 3 & 0 & 1 \\
\hline \multicolumn{5}{|c|}{ Strep. pneumoniae $(\mathbf{N}=3)$} \\
\hline & Ampicillin & 3 & 0 & 0 \\
\hline & Cefotaxime & 2 & 1 & 0 \\
\hline & Chloramphenicol & 3 & 0 & 0 \\
\hline & Ciprofloxacin & 3 & 0 & 0 \\
\hline & Cotrimoxazole & 0 & 1 & 2 \\
\hline & Erythromycin & 3 & 0 & 0 \\
\hline
\end{tabular}

\section{Discussion}

There is a need for periodic review of meningitis worldwide since the pathogens responsible for infection vary with time, geography and patient's age. Increase in awareness and availability of vaccines may also reflect a change in the epidemiological pattern of these pathogens. Thus, this paper attempts to explore the etiological agents of meningitis and the antibiotic susceptibility of bacterial isolates identified.

Only $16(4.5 \%)$ pathogens were isolated from 356 processed CSF samples. This isolation rate was similar to various studies conducted in Nepal. A study conducted by (Shaw et al., 2007) in Manipal Teaching 
Hospital, Nepal from 2000 to 2005 demonstrated 4.58\% growth on CSF culture. Similarly in a study carried out in between 2004 to 2008 by (Rijal et al., 2010), 4.4\% growth on CSF culture was observed.

But in contrary to these findings, (Bhagawati et al., 2014) reported $16.14 \%$ pathogens (fungal and bacterial) from CSF culture. A very high proportion (63.3\%) of culture positive result was also reported by (Ataee et al., 2011). A study carried out by (Adhikari and Wijesinghe, 2008-2009) in Kanti Children Hospital and TUTH, Nepal under South Asian Pneumoccocal Alliance Network showed $8.2 \%$ CSF culture growth positive. The isolation rate of pathogens was found to be comparatively low in this study. This may be due to fastidious nature of the organism and /or intake of antibiotics before presentation for treatment at the hospital.

This study demonstrated no any statistically significant difference between the age groups $(<14$ years and $\geq 14$ years) and the incidence of meningitis. This might be due to low number of positive cases encountered in this study. But in contrary, (Farag et al., 2005) showed that acute bacterial meningitis has a significant association with children of age group 1-9 years and asceptic meningitis was also found to be significantly associated with children aged 3-15 months. Statistically significant difference in the occurrence of bacterial meningitis with age group up to two years was also observed in a study of (AL-Zubiery, 2001). Similarly, no significant association between the sex of the patients and incidence of meningitis was established in this study. This finding is in agreement with the findings of (AL-Zubiery, 2001) where no significant association was observed between males and females less than two years of age and incidence of bacterial meningitis.

Upon CSF examination, the culture results revealed only two types of etiologies of meningitis; bacterial and fungal. The bacterial isolates accounted for $13(81.3 \%)$ and fungal isolates $3(18.8 \%)$ where $C$. neoformans was the only fungal isolate identified in this study. This finding is in agreement with the findings of a similar hospital based study conducted by (Mengistu et al., 2011) conducted in Ethiopia where they found $84.6 \%$ bacterial isolates and $15.4 \%$ fungal isolates in which $C$. neoformans was the only fungal isolate.

In this study the most common organisms responsible for bacterial meningitis were Staph. aureus (25\%), followed by Strep. pneumoniae $(18.8 \%)$ and E. coli (18.8\%), H. influenzae (6.3\%), Ps. aeruginosa (6.3\%) and $\mathrm{Kl}$. pneumoniae $(6.3 \%)$. This finding also showed a clear difference in the etiological agents of meningitis between children and adults. For children, bacterial were more dominant whereas $C$. neoformans was dominant among patients aged $>30$ years old.
C. neoformans was confirmed in two cases in the old aged patients ( $>60$ years) and in one case, in patient aged between $30-60$ years of age in this study. This may not mean that this is the most vulnerable group but may actually be a reflection of the fact that most of the hospital based population in this study falls in that age category. However, it could also be agreed with the view of (Bicanic and Harrison, 2004) that quotes that cryptococcal meningitis is a common opportunistic infection in AIDS patients, particularly in Southeast Asia and Africa. Such cases also occur in patients with other forms of immune-suppression and in apparently immune-competent individuals. But due to the low occurrence of $C$. neoformans in our sample series we cannot comment on its incidence by age group.

Staph. aureus remains the leading etiological agent isolated from CSF culture for bacterial meningitis over the study period. Staph. aureus was found mostly in the children of the age group 1-14 years and adults of the age group 14-30 years. This finding is in agreement with the finding of (Bhagawati et al., 2014) where the predominant organism isolated from CSF culture, was found to be Staph. aureus 15(29.41\%). Higher prevalence of meningitis due to Staph. aureus may be due to predisposing factors as well as co-morbidities associated with the patient.

The isolation rate of pathogens was recorded highest among the purulent $(75 \%)$ and cloudy (53.8\%) CSF sample in this study. Cloudy CSF indicates higher levels of protein, white and red blood cells and/or bacteria and therefore may suggest bacterial meningitis (Tunkel et al., 2004). Thus the initial appearance of the CSF may provide an indication of the nature of the infection.

Gram's stain identified more (19 isolates 5.3\%) isolates than culture (16 isolates, $4.5 \%$ ) of total clinically suspected cases of meningitis. This finding is similar to the finding of Rao et al. (1998) in which more isolates on Gram staining $85.7 \%$ ( 66 out of 77 cases) than on CSF culture (48 isolates) was found. The lower rate of the culture result of the pathogens in this study may be due to the fastidious and delicate nature of the organisms.

Ampicillin, Chloramphenicol, Ciprofloxacin and Erythromycin were found to be $100 \%$ effective against Strep. pneumoniae in the present study which is comparable with the findings of (Bhagawati et al., 2014) where Strep. pneumoniae was found to be 50,100 and $100 \%$ susceptible towards Chloramphenicol, Ciprofloxacin and Erythromycin respectively. But the remarkable finding of this study is the level of Cotrimoxazole resistance and the result is in accordance with the findings of the study carried out in Bangladesh by Saha et al. (1999). The increased resistance to Cotrimoxazole can possibly be correlated with the wide use this antibiotic in the communities because of its dose convenience, cost effectiveness and easy availability over the counter. 
All antibiotics used for Staph. aureus, in this study, were found to be sensitive in greater than $65 \%$ cases in the present study. This finding is almost comparable to the finding of Chugh et al. (2011) except for Chloramphenicol (where Amikacin-87.5\%, Cefotaxime$50 \%$, Ceftazidime- $75 \%$ effective against Staph. aureus).

$H$. influenzae was found to be resistant to only Ampicillin in the present study. In a study, carried out by Nag et al. (2001) in India, H. influenzae was found to be resistant against both Cotrimoxazole (33.3\%) and Ampicillin (21.7\%). The differences in antibiotic resistance pattern may be due to geographical variations, local antibiotics prescribing habits and selection of cases.

Chloramphenicol was $100 \%$ effective for $E$. coli which is comparable to the finding of Mengistu et al. (2013). In a similar study by (Kibret and Abera, 2011), Chloramphenicol was found to be $63.2 \%$ effective against $E$. coli. E. coli was found to be $33.3 \%$ resistant to Ceftriaxone and $66.7 \%$ susceptible with Ceftriaxone in the present study which is exactly similar to the findings of a study carried out in Nigeria by Iregbu et al. (2013). E. coli was resistance to Amikacin (66.7\%) and Cotrimoxazole (66.7\%) in this study. Kibret and Abera (2011) also reported $62.9 \%$ resistance of $E$. coli. against Cotrimoxazole. Because antimicrobial resistance patterns are continually evolving and E. coli invasive isolates undergo progressive antimicrobial resistance, continuously updated data on antimicrobial susceptibility profiles will continue to be essential to ensure the provision of safe and effective empirical therapies.

Kl. pneumoniae was found to be resistant against Amikacin and Ciprofloxacin in this study and other antibiotics such as Cefotaxime, Chloramphenicol, Cotrimoxazole and Ofloxacin were found to be effective against $\mathrm{Kl}$. pneumoniae. In contrary to this result, Shaw et al. (2005) reported Amikacin (58.3\%) and Ciprofloxacin (91.7\%) sensitive against $\mathrm{Kl}$. pneumoniae. They also found that Cefotaxime $(83.3 \%)$ and Ofloxacin (91.7\%) were sensitive as comparable to the present study. Due to low incidence of $\mathrm{Kl}$. pneumoniae in this study, we cannot comment on the contradictory result about the susceptibility pattern of this pathogen.

All the antibiotics used against Ps. aeruginosa in this study were found to be sensitive except Gentamicin. Taneja et al. (2009) also reported that Meropenem (70\%), Amikacin (70\%) and Ofloxacin (40\%) were effective against Ps. aeruginosa which is comparable to this study.

\section{Implications}

Due to absence of appropriate surveillance, poor bacterial detection methods and social and health care barrier to disease reporting, the cases of meningitis may be underrecognized in some regions of the world like Nepal. Thus the findings of this study possess a worthy move in the direction of periodic update of the etiology of meningitis. The paper also emphasizes on the antibiotics susceptibility profile of bacterial isolates. Such type of study is vital in developing countries like Nepal where local antibiotics prescribing habit exists very often. As a result of which, antimicrobial patterns are continually evolving. So such study is beneficial for local medical practitioners to ensure the provision of safe and effective empirical therapies and reducing antibiotics misuse.

\section{Conclusion}

The isolation rate of pathogens causing meningitis is low $(4.5 \%)$. This may be probably due to the fastidious nature of the organisms or prior exposure to antibiotics. Staph. aureus is the predominant bacterial isolate and $C$. neoformans is the only leading cause of fungal meningitis in this study. If bacterial meningitis is suspected on admission or at any later stage of management of patients, initial antibiotics therapy with Chloramphenicol may be under taken as it is found sensitive against all bacterial isolates identified in this study. However, empirical treatment with such antibiotics is recommended only in life threatening cases under medical doctor's prescription due to its fatal side effect.

\section{Acknowledgement}

We acknowledge all the staffs of Emergency Laboratory of TUTH, Nepal for their cooperation during the laboratory work.

\section{Author's Contributions}

All co-authors were involved in the conception and design of the study and analysis and interpretation of the data. All authors read and approved the final manuscript.

\section{Conflict of Interest}

No conflict of interest to declare.

\section{References}

Adhikari, R.K. and P.R. Wijesinghe, 2008-2009. Surveillance of invasive pneumococcal disease among children aged 2-59 months in Nepal and Sri Lanka (SAPNA Phase III). Nepal and Sri Lanka: South Asian Pneumococcal Alliance (SAPNA).

Al Bekairy, A.M., S. Al Harbi, A.M. Alkatheri, S. Al Dekhail and L. Al Swaidan et al., 2014. Bacterial meningitis: An update review. Afr. J. Pharmacy Pharmacol., 8: 469-478. DOI: $10.5897 / A J P P 2014.4042$

AL-Zubiery, T.K.A., 2001. Bacterial meningitis among children in Sana`a/Yemen. MSc Thesis, Sana`a University, Sana, Yemen. 
Andargachew, M., K. Afework and T. Belay, 2005. Bacterial isolates from cerebrospinal fluids and their antibiotic susceptibility patterns in Gondar University Teaching Hospital, Northwest Ethiopia. Ethiopian J. Health Develop., 19: 160-164. DOI: 10.4314/ejhd.v19i2.9986

Ansari, I. and Y. Pokhrel, 2011. Culture proven bacterial meningitis in children: Agents, clinical profile and outcome. Kathmandu Uni. Med. J., 9: 36-40. PMID: 22610807

Ataee, R.A., A. Mehrabi-Tavana, M. Izadi, S.M.J. Hosseini and M.H. Ataee, 2011. Bacterial meningitis: A new risk factor. J. Res. Med. Sci., 16: $207-210$

Bhagawati, G., D. Barkataki and N.K. Hazarika, 2014. Study on isolates of acute meningitis in a tertiary care centre in Assam. Int. J. Med. Public Health, 4: 446-450. DOI: $10.4103 / 2230-8598.144132$

Bicanic, T. and T.S. Harrison, 2004. Cryptococcal meningitis. Br. Med. Bull., 72: 99-118. DOI: $10.1093 / \mathrm{bmb} / \mathrm{ldh} 043$

CDC, 1998. Laboratory methods for the diagnosis of meningitis caused by Neisseria meningitidis, Streptococcus pneumoniae and Haemophilus influenzae. World Health Organization.

CDC, 2015a. Fungal meningitis.

CDC, 2015b. Viral meningitis.

Ceyhan, M., I. Yildirim, P. Balmer, R. Borrow and B. Dikici et al., 2008. A prospective study of etiology of childhood acute bacterial meningitis, Turkey. Emerging Infec. Dis., 14: 1089-1095. DOI: 10.3201/eid1407.070938

Chugh, Y., A.K. Kapoor, N. Kastury, A.K. Srivastava and A. Bhargava et al., 2011. Study of antimicrobial sensitivity pattern of Gram-positive CSF isolates among children suffering from septic meningitis in a tertiary care hospital. J. Indian Academy Clin. Med., 12: 274-282.

Davison, K.L. and M.E. Ramsay, 2003. The epidemiology of acute meningitis in children in England and Wales. Arch. Dis. Childhood, 88: 662-664. DOI: 10.1136/adc.88.8.662

Farag, H.M., M.M. Abdel-Fattah and A.M. Youssri, 2005. Epidemiological, clinical and prognostic profile of acute bacterial meningitis among children in Alexandria, Egypt. Indian J. Med. Microbiol., 23: 95-101. DOI: 10.4103/0255-0857.16047

Iregbu, K.C., K.O. Zubair, I.F. Modibbo, A.I. Aigbe and S.A. Sonibare et al., 2013. Neonatal infections caused by Escherichia coli at the National Hospital, Abuja: A three-year retrospective study. Afr. J. Clin. Experimental Microbiol., 14: 95-100.

DOI: $10.4314 /$ ajcem.v14i2.9
Kibret, M. and B. Abera, 2011. Antimicrobial susceptibility patterns of $E$. coli from clinical sources in northeast Ethiopia. African Health Sci., 11: S40-S45. DOI: 10.4314/ahs.v11i3.70069

Laving, A.M.R., R.N Musoke, A.O. Wasunna and G. Revathi, 2003. Neonatal bacterial meningitis at the newborn unit of Kenyatta National Hospital. East Afr. Med. J., 80: 456-462.

Mahmoud, F.S. and B.R. Abd-ElSadik, 2013. Effect of clinical pathway regarding promoting quality nursing care of children with meningitis exposed to invasive procedures. J. Am. Sci., 9: 383-393.

Mengistu, A., J. Gaeseb, G. Uaaka, C. Ndjavera and K. Kambyambya et al., 2013. Antimicrobial sensitivity patterns of Cerebrospinal Fluid (CSF) isolates in Namibia: Implications for empirical antibiotic treatment of meningitis. J. Pharmaceutical Policy Practice, 6: 4. DOI: 10.1186/2052-3211-6-4

Mengistu, M., D. Asrat, Y. Woldeamanuel and G. Mengistu, 2011. Bacterial and fungal meningitis and antimicrobial susceptibility pattern in Tikur Anbessa University Hospital, Addis Ababa, Ethiopia. Ethiopian Med. J., 49: 349-359. PMID: 23409400

Nag, V.L., A. Ayyagari, V. Venkatesh, M. Ghar and V. Yadav et al., 2001. Drug resistant haemophilus influenzae from respiratory tract infection in a tertiary care hospital in North India. Indian J. Chest Dis. Allied Sci., 43: 13-17. PMID: 11370501

Nagarathna, S., A. Chandramuki and H.B. Veenakumari, 2012. Laboratory Diagnosis of Meningitis. 1st Edn., INTECH Open Access Publisher, ISBN-10: 9535103830.

Rao, B.N., I.M. Kashbur, N.M. Shembesh and S.M. El-Bargathy, 1998. Etiology and occurrence of acute bacterial meningitis in children in Benghazi Libyan Arab Jamahiriya. Eastern Mediterranean Health J., 4: 50-57.

Rijal, B., S. Tandukar, R. Adhikari, N.R. Taludhar and P.R. Sharma et al., 2010. Antimicrobial susceptibility pattern and serotyping of Streptococcus pneumoniae isolated from Kanti Children Hospital in Nepal. Kathmandu Uni. Med. J., 8: 164-168. DOI: 10.3126/kumj.v8i2.3551

Saha, S.K., N. Rikitomi, M. Ruhulamin, H. Masaki and M. Hanif et al., 1999. Antimicrobial resistance and serotype distribution of streptococcus pneumoniae strains causing childhood infections in Bangladesh, 1993-1997. J. Clin. Microbiol., 37: 798-800.

Schuchat, A., K. Robinson, J.D. Wenger, L.H. Harrison and M. Farley et al., 1997. Bacterial meningitis in the United States in 1995. The New England J. Med., 337: 970-976. DOI: 10.1056/NEJM199710023371404 
Shaw, C.K., P. Shaw and A. Thapalial, 2007. Neonatal sepsis bacterial isolates and antibiotic susceptibility patterns at a NICU in a tertiary care hospital in western Nepal: A retrospective analysis. Kathmandu Uni. Med. J., 5: 153-160.

Sung, R.Y.T., A.C. Senok, A. Ho, S.J. Oppenheimer and D.P. Davies, 1997. Meningitis in Hong Kong children, with special reference to the infrequency of haemophilus and meningococcal infection. J. Paediatrics Child Health, 33: 296-2999. DOI: 10.1111/j.1440-1754.1997.tb01603.x

Taneja, J., B. Mishra, A. Thakur, P. Loomba and V. Dogra, 2009. Pseudomonas aeruginosa meningitis in post neurosurgical patients. Neurol. Asia, 14: 95-100.
Tunkel, A.R., B.J. Hartman, S.L. Kaplan, B.A. Kaufman and K.L. Roos et al., 2004. Practice guidelines for the management of bacterial meningitis. Clin. Infect. Dis., 39: 1267-1284. DOI: $10.1086 / 425368$

WHO, 2005. Enhanced surveillance of epidemic meningococcal meningitis in Africa: A three-year experience. Weekly Epidemiol. Record, 80: 313-320.

Wilder-Smith, E., K.M. Chow, R. Kay, M. Ip and N. Tee, 2000. Group B streptococcal meningitis in adults: Recent increase in Southeast Asia. Aus. N. Zealand J. Med., 30: 462-465.

DOI: $10.1111 /$ j.1445-5994.2000.tb02052.x 